\title{
Transfer Benefit Evaluation on University S\&T Achievements Based on Bootstrap-DEA
}

\author{
Feng $\mathrm{Di}^{1}$ \\ Taiyuan University of Technology
}

\begin{abstract}
The performance evaluation on the transfer of Science and Technology(S\&T) achievements in universities has important implications for knowing through the current situation of this area and strengthening the regulation and management capacities of the social macroeconomy. However, there are still some divergences of opinions on how to recognize the basic issues in academic circles, for example, what are the concept and the model of S\&T achievements transfer, and what' $s$ the standard for successful S\&T transfer. After the analysis of the above three issues, and the concepts of $S \& T$ achievement and the pure technology transfer are actively compared, the input and output elements in the S\&T achievement transfer process in universities are extracted, among which, inputs include various types of applications as S\&T achievements including patents; the outputs refer to the three transfer behaviors, i.e. technology transfer, licensing and valuation investment. Based on these inputs and outputs, the transfer efficiencies of S\&T achievements from some universities in China in 2010-2017 are surveyed using the Bootstrap-DEA method. The findings suggest: the average transfer efficiencies of S\&T achievements in universities in 2001, 2002, 2008 and 2009 are 0.64, 0.78, 0.77 and 0.81, respectively, which shows the Chinese universities present a continuously improved evolution trend in this regard. The standards for the transfer efficiency of S\&T achievements in universities are $0.20,0.18,0.16$ and 0.18 , respectively. It means that the gap in the transfer efficiency of $S \& T$ achievements between universities has not shown a downward trend.
\end{abstract}

\section{Keywords}

Transfer of S\&T Achievements • Technology Transfer • Input Indicators • Output Indicators

${ }^{1}$ Correspondence to: Feng Di (PhD), College of Economic and Management, Taiyuan University of Technology, Taiyuan 030024, China. Email: difeng0815@163.com

Citation: Di, F., Transfer Benefit Evaluation on University S\&T Achievements Based on Bootstrap-DEA. Educational Sciences: Theory \& Practice, 18(5), 1125-1137. http://dx.doi.org/10.12738/estp.2018.5.014 
Universities, as the undertakers of technology innovation in China, will develop the huge number of S\&T achievements each year. How to transform these S\&T achievements into real productivity and improve the benefits of S\&T inputs is a common challenge that all universities face now. When combing the existing pertinent literature, it is found that the evaluation standards for the transfer benefits of S\&T results, as many literature involve, can be roughly classified into three types: 1 . the absolute quantitation, Zhao and Du, (2011) for example, proposed a set of indicators that enables a dynamic monitoring on the S\&T transfer effect based on the types of S\&T results and the differentials in the transfer process; 2 . the transfer rate of S\&T results, that is, a part for successful industrialization applications as percentage of the total. When calculating it, the number of patent applications or patents granted is used as the denominator, and the number of patents transferred and licensed as molecules (Cai, 2015). This is an idea of relative efficiency evaluation. Commonly used in the mass media, it is just required to choose more input and output indicators to evaluate the benefits with the SFA (Stochastic Frontier Analysis) or DEA (Data Envelopment Analysis). For example, He and Fan, (2013) chose seven indicators such as R\&D expenditure, the number of academic papers published abroad, etc., to measure the inputs of the universities' S\&T transfer process, as well as the outputs such as the number of patent grants and transference of patients. They evaluated the transfer rate of S\&T results from 24 universities using the DEA method.

From the above three types of literature, there are the gaps in the selection of indicators:1, there are different opinions on how to define S\&T results (i.e. inputs) and the successful transfer standards (i.e. outputs). Some studies believe that input factors of the S\&T transfer process are those results that have potential market application value, while some literature suggest that the results produced by various S\&T activities should be included, such as journal articles, R\&D expenditure, HR, and other inputs factors. From the outputs of the S\&T transfer process, some scholars also believe that the inputs that "have not accessed to the economic benefit" and "have not been industrialized" all pertain to incomplete transfer processes (He, 2011), but those literature involving physical measurement of relative efficiency rarely refer to these criteria. 2. most of the literature uses patents as the representatives of the results with wide potential application in the market, rarely involves software registration, integrated circuit design, new animal and plant registration, national-level new drug registration, and other intellectual property rights that will not be patented. 3 . most studies only evaluate the effects of technology licensing and transfer of traditional results that are the most widely used for transfer mechanisms, and rarely focus on the transfer mechanism of valuation investment (Zhao, Zhang, Tang \& Di, 2011). In order to make up for the above gaps, this paper analyzes the concept, mechanism and success standards of S\&T achievement transfers, and compares it with the technology transfer at a conceptual level. Based on theoretical analysis, the input and output factors of the S\&T transfer process in universities are extracted. Among them, inputs include various types of application-oriented S\&T achievements such as patents, and the outputs involve three behaviors, i.e. technology transfer, licensing and valuation investment. Given these inputs and outputs, the Bootstrap-DEA method is introduced to evaluate and compare the transfer benefits of S\&T results in universities. This paper concerns with the relative efficiency, but the idea of choosing the indicators also applies to the absolute quantitation evaluation process.

Scholars usually measure the efficiency of multi-inputs and multi-outputs production processes in two ways (Coelli, Rao, O'donnell \& Battese, 2005): SFA-based parametric method and DEA-based nonparametric 
methods. The former estimates the frontier production function quantitatively, that is, it is supposed there is a definite production function expression between inputs and outputs, where the parameters are estimated under certain conditions based on a set of observation data about inputs and outputs. The latter builds the production functions with the mathematical linear programming technique to measure the transfer efficiency, that is, the production frontiers are estimated by the piecewise convex function approximation, and the decision unit falling over the frontier has the maximum efficiency. Other decision units and their linear combinations will be unable to yield more in the case when the inputs are well-established, nor can they get outputs as specified with less inputs, so that the transfer efficiency is low.

From the transfer efficiencies of S\&T results and technologies, the findings of scholars suggest that these two methods are complementary. Some scholars apply the DEA method (Anderson, Daim \& Lavoie, 2007), but some introduce the SFA method (Siegel, Waldman \& Link, 2003; Li and Yu, 2014). In view of the fact that this paper focuses more on the measurement of transfer efficiency itself than the impact factors, and that the DEA method more applies to measure the production process of multiple outputs, this paper uses the DEA method for benefit evaluation and choose the classic CCR model to calculate the transfer efficiency, which represents the integration of the management level and scale effect of S\&T results transfer in universities. DEA is a method for evaluating the relative efficiency of decision units with homogeneous inputs and outputs. Compared with SFA, DEA has the following advantages: (1) DEA method applies to evaluate the relative efficiency of decision units with multiple inputs and outputs. The decision units studied in this paper have multiple inputs such as capitals, manpower, patents, etc., and multiple outputs including new product sales revenue, technology market contract amount, and high-tech industry added value, etc. Therefore, the DEA method is more superior. (2) The SFA method needs to construct the frontier of observation data with the production functions, while the DEA method obtains it via the mathematical linear programming technique without weighting assumption, and has a stronger objectivity. (3) The inputs and outputs indicators in each decision unit do not need to be dimensionless, which makes the calculation process simpler. (4) The DEA method assumes that there is a correlation between the inputs and outputs of the decision units, but it is not required to determine the relational expression. The SFA and DEA methods are different from each other in the terms of application scope and measurement effect, but thanks to the advantages of DEA method, this paper uses the DEA to evaluate the transfer efficiency of S\&T results in Shanxi Province, China. Next, the principle of the DEA model is elaborated to provide the clues to the calculation of the subsequent study cases. In order to correct the errors caused by the impact of random factors on the efficiency evaluation, this paper also uses the Bootstrap-DEA method for troubleshooting these.

\section{Bootstrap-DEA model}

Ignored the impact of random factors, an error occurs in the traditional DEA model when estimating the efficiency, so that it is also cumbersome to use it for statistical inference. Simar \& Wilson (2000) developed a general method that applies Bootstrap to nonparametric frontier model estimation, which better solved this problem, as shown below: 
(1) The original input-output dataset is used, for each decision unit, $D M U_{j}(\mathrm{j}=1,2, \ldots, \mathrm{n})$, and the DEA method is used to calculate the efficiency value $\theta_{j}$.

(2) Extract the samples $\theta_{1 b}, \ldots, \theta_{n b}(b=1,2, \ldots, \mathrm{B})$ of size $n$ from $\theta_{1}, \ldots, \theta_{n}$ by repeated sampling, where $b$ represents the repeated sampling busing the Bootstrap method.

(3) Smooth the samples $\theta_{1 b}, \ldots, \theta_{n b}$ to obtain final sample values $\theta_{1 b}^{*}, \ldots, \theta_{n b}^{*}$. The smoothing formula is:

$$
\theta_{j b}^{*}=\bar{B}+\frac{\tilde{\theta}_{j b}^{*}-\bar{B}}{\left(1+h^{2} / \hat{\sigma}_{0}^{2}\right)^{1 / 2}}
$$

Where: $\bar{B}=\frac{1}{n} \sum_{j=1} \theta_{j b}, \tilde{\theta}_{j b}^{*}=\left\{\begin{array}{c}\theta_{j b}+h \varepsilon_{j}^{*} i f \theta_{j b}+h \varepsilon_{j}^{*} \geq 1 \\ 2-\theta_{j b}-h \varepsilon_{j}^{*} \text { if } \theta_{j b}+h \varepsilon_{j}^{*}<1\end{array}, \hat{\sigma}_{0}{ }^{2}=\frac{1}{n} \sum_{j=1}\left(\widehat{\theta_{J}}-\widehat{\overline{\theta_{J}}}\right)\right.$ 。

Where $\mathrm{h}$ is the smoothing parameter or bandwidth; $\varepsilon$ is the random error term.

(4) $\widehat{\theta_{J b}} / \theta_{j b}{ }^{*}$ is used to adjust the original input data $x_{j}$ to obtain: $x_{j b}{ }^{*}=\left(\widehat{\theta_{J b}} / \theta_{j b}{ }^{*}\right) x_{j}$.

(5) The DEA efficiency $\widehat{\theta_{J b}}$ is recalculated with the input data $x_{j b}{ }^{*}$ and the original output data.

(6) Repeat the steps (2)-(5) for B times to obtain ${\widehat{\theta_{J b}}}^{*},(b=1, \ldots, B)$.

(7) Calculate the offset, the corrected efficiency value and the confidence interval, bias: $\widehat{\text { bias }}\left(\widehat{\theta}_{J}\right)=$ $B^{-1} \sum_{b=1}^{B}{\widehat{\theta_{J b}}}^{*}-\widehat{\theta}_{J}$, the corrected efficiency value: $\widehat{\hat{\theta}_{J}}=\widehat{\theta_{J}}-\widehat{\text { bias }}\left(\widehat{\theta}_{J}\right)=2 \widehat{\theta}_{J}-B^{-1} \sum_{b=1}^{B} \theta_{j b}{ }^{*}$.

If the confidence level is $\alpha$, according to $\operatorname{Pr}\left(-b_{\alpha} \leq \widehat{\theta}_{J}^{*}-\widehat{\theta}_{J} \leq-a_{\alpha}\right)=1-\alpha, \mathrm{B} \widehat{\theta}_{J}^{*}-\widehat{\theta}_{J}$ are sorted in ascending order, then remove the value of $100 \alpha / 2 \%$ in the first place, and the endpoint values at both ends are $-\widehat{b_{\alpha}}$ and $-\widehat{a_{\alpha}}$. Then, a confidence interval can be available: $\widehat{\theta_{J}}-\widehat{a_{\alpha}} \leq \theta_{j} \leq \widehat{\theta_{J}}+\widehat{b_{\alpha}}$.

\section{Indicator selection and case evaluation}

\section{Inputs indicator}

The scientific and reasonable evaluation indicator is the premise for accurately measuring the transfer efficiency of S\&T achievements in Shanxi, China. After quantitative analysis of relevant data in the early stage, it can be concluded that the efforts of many scholars have borne rich fruits in the study of the evaluation indicators for S\&T transfer efficiency. These usually include two types: inputs and outputs indicators. Combining with the existing literature, we learn that the inputs indicators for evaluating the S\&T transfer efficiency mainly include HR, capitals and intellectual properties. In essence, the innovation is driven by talents. The success of S\&T transfer is inseparable from a large pool of high-quality professional talents. Data that can reflect human inputs include $R \& D$ personnel, $R \& D$ researchers' full-time equivalents, S\&T campaigners, etc. Capital investment is not only fundamental to S\&T transfer, but also an important precondition of it. Its indicators mainly include internal expenses of R\&D funds, S\&T working outlay, and new product development 
costs, etc. The patents applied and granted, and the S\&T papers included in the three core journals mainly reflect the inputs of intellectual properties in the transfer of $S \& T$ achievements.

In the interpretation of statistical indicators of the National Bureau of Statistics, the R\&D refers to the systematic and creative activities in the field of science and technology, which intend to increase the collective sum of world's knowledge and apply them to create new systems, including three types of activities, i.e. basic research, applied research, experimental development. Among them, the last experimental development is defined as the tasks done by such a way that the existing knowledge available from basic research, applied research and practical experience is harnessed to create new processes, systems and services for new products, materials and devices, as well as the systematic works, for example, to improve the generated and wellestablished items as mentioned above substantially. It can better reflect the process that the S\&T results are transformed into products. In view of this, the paper chooses the R\&D HR's experiment developers to convert the full-time equivalent, and as the $R \& D$ overhead expenditure internally, experimental development funds are used as human input and capital investment for the transfer of S\&T results. As stipulated in the National Patent Laws, patents include the inventions, utility models and appearance designs. Among them, the inventions for new technologies feature novelty, creativity and practicality. It will be transformed into products more easily than other two patents, and better reflect the innovation of results. Those inventions that are not granted are not under the national protection, so that the patents granted can reflect the inputs of knowledge more than that patent applications.

Table 1

Economic Benefits Indicators

\begin{tabular}{|c|c|c|}
\hline $\begin{array}{l}\text { Destination } \\
\text { layer }\end{array}$ & Domain layer & name of evaluation indicator \\
\hline \multirow{11}{*}{$\begin{array}{l}\text { Economic } \\
\text { benefits }\end{array}$} & \multirow{4}{*}{$\begin{array}{l}\text { Income from intangible } \\
\text { technology products }\end{array}$} & Trademark licensing revenue \\
\hline & & Research consulting income \\
\hline & & Commissioned education income \\
\hline & & Revenue from technical services \\
\hline & \multirow{3}{*}{$\begin{array}{l}\text { Income from tangible technology } \\
\text { products }\end{array}$} & New product sales revenue \\
\hline & & $\begin{array}{l}\text { Income from transfer of scientific and } \\
\text { technological achievements }\end{array}$ \\
\hline & & New product export sales revenue \\
\hline & New profit & New profit for the year \\
\hline & \multirow{3}{*}{$\begin{array}{l}\text { Production efficiency } \\
\text { improvement }\end{array}$} & Cost of production reduced amount \\
\hline & & Increase in input to output ratio \\
\hline & & Increase in fixed assets \\
\hline
\end{tabular}

\section{Outputs indicator}

Universities are the bases for producing $S \& T$ results and cultivating $S \& T$ talents. Every year, there are a large number of scientific payoffs and S\&T talents, which provide important clues for the evaluation of the benefits of S\&T transfers in universities. In order to make the well-established indicators not only be able to evaluate the general strength of $S \& T$ achievements transfer in different universities, but also work well with various functional subsystems in the system. This paper proposes an integrative evaluation system for the transfer benefits of S\&T results in universities, considering the three levels, i.e. S\&T innovation. social benefits and economic benefits, there are 30 indicators involved in total. The combination of quantitative, qualitative 
indicators is used to evaluate the current situation, existing problems and development trend of the S\&T results transfer model in universities.

Economic benefits of university S\&T results transfer. The economic benefit of S\&T achievement transfer is a key factor to measure the $S \& T$ achievement transfer efficiency in universities. As an external representation of the S\&T achievements transforming into real productivity. The indicator can be expressed by the incomes of intangible and tangible technology products, additional profits, and improvement of production efficiency, etc. There are 11 indicators in this level. As shown in Table 1.

Social benefit indicators for university S\&T achievement transfer. The social benefit indicator for S\&T achievement transfer in universities refers to the contribution to the social employment, increasing profits and taxes, and making technological progress. The contribution to promote employment mainly refers to the number of new jobs in the year; the contribution of increasing profits and taxes mainly refers to the newly added profits and taxes in the current year; the contribution of technological progress mainly refers to the contribution rate of technological advancement and the growth rate of labor productivity of all employees. The set of indicators at this level includes four indicators, as shown in Table 2.

Table 2

Social Benefits Indicators

\begin{tabular}{lll}
\hline Destination layer & \multicolumn{1}{c}{ Domain layer } & \multicolumn{1}{c}{ Name of evaluation indicator } \\
\cline { 2 - 3 } social benefits & Employment promotion contribution & The number of new jobs that year \\
\cline { 2 - 3 } & Profit tax contribution & New profits and taxes \\
\cline { 2 - 3 } & Contribution to technological progress & Contribution rate of technological progress \\
\cline { 2 - 3 } & & Total labor productivity growth rate \\
\hline
\end{tabular}

S\&T Innovation indicators for the university S\&T achievement transfer. It refers to the attainment in S\&T innovation area in the process of S\&T achievement transfer, including technical transaction, awardwinning achievement, and patent. The technical transaction indicator is mainly reflected by the volume and the number of technical transactions; the award-winning indicator are measured by the number of awards at the world, national, provincial, and municipal level; the patent indicator pertains to patent applications accepted and patents granted in domestic and international markets. The indicators set at this level consists of nine indicators, as shown in Table 3.

Table 3

Scientific and Technological Innovation Indicators

\begin{tabular}{lll}
\hline Destination layer & \multicolumn{1}{c}{ Domain layer } & \multicolumn{1}{c}{ Name of evaluation indicator } \\
\cline { 2 - 3 } & Technology to clinch a deal & The amount of technical contract transaction \\
\cline { 2 - 3 } $\begin{array}{l}\text { Scientific and } \\
\text { technological } \\
\text { innovation }\end{array}$ & The winning achievements & Number of technical contracts concluded \\
\cline { 2 - 3 } & Patent & The number of national awards \\
\cline { 2 - 3 } & & Provincial and ministerial achievements \\
\cline { 2 - 2 } & & The number of local and municipal achievements \\
\hline
\end{tabular}

According to the principle of selecting the benefit evaluation indicators for the S\&T achievement transfer in universities, some king factors affecting the transfer efficiency of S\&T achievements in universities are selected 
as evaluation indicators to build the evaluation indicator system for the transfer benefits of S\&T achievements in universities, as shown in Table 4. Such system in Chinese universities includes three secondary indicators, i.e. economic and social benefits, S\&T innovation, and a total of 24 three-level indicators. Each of the secondary indicators is composed of several three-level indicators, for example, the economic benefit indicator includes 11 three-level indicators; social benefit indicator consists of four three-level indicators; S\&T innovation indicator has nine secondary indicators. See Table 4 for details.

Table 4

Pre-election Evaluating Indicator System in The Operation Performance of The Universities' Scientific and Technological Achievements

\begin{tabular}{|c|c|c|c|}
\hline \multirow{25}{*}{$\begin{array}{l}\text { Performance evaluation } \\
\text { of university scientific } \\
\text { and technological } \\
\text { achievements operation } \\
\text { mode }\end{array}$} & $\begin{array}{l}\text { The secondary } \\
\text { indicators }\end{array}$ & The third indicators & $\begin{array}{l}\text { The index } \\
\text { code }\end{array}$ \\
\hline & \multirow{11}{*}{$\begin{array}{l}\text { Economic benefit } \\
\text { B1 }\end{array}$} & Trademark licensing revenue & B11 \\
\hline & & Research consulting income & B12 \\
\hline & & Commissioned education income & B13 \\
\hline & & Revenue from technical services & B14 \\
\hline & & New product sales revenue & B15 \\
\hline & & $\begin{array}{l}\text { Income from transfer of scientific and } \\
\text { technological achievements }\end{array}$ & B16 \\
\hline & & New product export sales revenue & B17 \\
\hline & & New profit for the year & B18 \\
\hline & & Cost of production reduced amount & B19 \\
\hline & & Increase in input to output ratio & B110 \\
\hline & & Increase in fixed assets & B111 \\
\hline & \multirow{4}{*}{ Social benefit B2 } & The number of new jobs that year & B21 \\
\hline & & New profits and taxes & $\mathrm{B} 22$ \\
\hline & & $\begin{array}{l}\text { Contribution rate of technological } \\
\text { progress }\end{array}$ & B23 \\
\hline & & Total labor productivity growth rate & B24 \\
\hline & \multirow{9}{*}{$\begin{array}{l}\text { Scientific and } \\
\text { technological } \\
\text { innovation B3 }\end{array}$} & $\begin{array}{l}\text { The amount of technical contract } \\
\text { transaction }\end{array}$ & B31 \\
\hline & & Number of technical contracts concluded & B32 \\
\hline & & World-class achievement awards & B33 \\
\hline & & The number of national awards & B34 \\
\hline & & Provincial and ministerial achievements & B35 \\
\hline & & $\begin{array}{l}\text { The number of local and municipal } \\
\text { achievements }\end{array}$ & B36 \\
\hline & & $\begin{array}{l}\text { The volume of patent applications } \\
\text { accepted }\end{array}$ & B37 \\
\hline & & Number of international patents granted & B38 \\
\hline & & $\begin{array}{l}\text { Domestic authorization number of } \\
\text { patents }\end{array}$ & B39 \\
\hline
\end{tabular}

Key Indicator identification based on group eigenvalue method. In order to make the performance evaluation indicators for S\&T achievement transfer operation in China more scientific, reasonable, objective and effective, it is required to filtrate the candidate indicators. As strong correlation and repetitiveness may coexist between the three-level indicators, those with high correlation and that have little impact on the transfer operation performance of S\&T results should be removed. Then, key indicators should be identified. This paper adopts the GEM, that is, the abbreviation of Group Eigenvalue Method, as a relatively scientific and effective method for indicator selection, which has been used by many experts and scholars. As applicable to the study 
itself, this paper uses it for the performance evaluation of the S\&T results transfer in Chinese universities (Shen, 2010).

Key indicators of transfer performance evaluation of university S\&T results. In the process of performance evaluation on the S\&T results operation in universities, the GEM is used to evaluate the importance of key indicators to pick them out. A questionnaire survey was conducted among 20 experts from 211 universities nationwide and 18 valid questionnaires were collected. According to the scoring criteria of the evaluation indicators, taking the evaluation indicator of social benefits as an example, the scores rated by experts are shown in Table 5.

Table 5

Expert Rating Score for Social Benefits Evaluation Index

\begin{tabular}{|c|c|c|c|c|}
\hline & B21 & B22 & B23 & B24 \\
\hline S1 & 4 & 3 & 2 & 5 \\
\hline S2 & 5 & 2 & 1 & 4 \\
\hline S3 & 5 & 2 & 1 & 3 \\
\hline S4 & 4 & 2 & 3 & 3 \\
\hline S5 & 4 & 3 & 2 & 4 \\
\hline S6 & 5 & 1 & 2 & 4 \\
\hline S7 & 5 & 4 & 3 & 5 \\
\hline S8 & 5 & 2 & 1 & 5 \\
\hline S9 & 4 & 2 & 4 & 2 \\
\hline $\mathrm{S} 10$ & 4 & 3 & 3 & 5 \\
\hline S11 & 3 & 3 & 2 & 5 \\
\hline $\mathrm{S} 12$ & 4 & 4 & 3 & 4 \\
\hline S13 & 5 & 3 & 2 & 4 \\
\hline S14 & 3 & 3 & 2 & 3 \\
\hline S15 & 4 & 4 & 1 & 4 \\
\hline S16 & 3 & 2 & 1 & 3 \\
\hline S17 & 3 & 1 & 4 & 5 \\
\hline S18 & 5 & 5 & 3 & 5 \\
\hline
\end{tabular}

The expert's scoring data in Table 5 above is processed to obtain an initial scoring matrix $X_{18 \times 4}$.

$$
F=X^{T} X F=\left[\begin{array}{llll}
323 & 206 & 164 & 306 \\
206 & 153 & 110 & 204 \\
164 & 110 & 106 & 163 \\
306 & 204 & 163 & 311
\end{array}\right]
$$

The MATLAB is used to calculate its largest eigenvalue is a simple root $\rho_{\max }=849.4339$, the corresponding eigenvector is $B=\left[\begin{array}{llll}0.6085 & 0.4067 & 0.3256 & 0.5985\end{array}\right]$, therefore, its comprehensive scores $\mathrm{B}_{3}<\mathrm{B}_{2}<\mathrm{B}_{4}<\mathrm{B}_{1}$. The feature vector is unitized, $\mathrm{B}=\left[\begin{array}{llll}0.3053 & 0.2343 & 0.1634 & 0.3003\end{array}\right]$. This paper sets 0.3 as the reference value of the indicator selection, when the importance is less than 0.3 , it is clear that the indicator has a little impact on the overall objective results, so that it should be eliminated. Only those indicators with importance greater than 0.3 should be retained. By calculating B21, the importance of B24 is greater than the preset reference value of 0.3 , so that it should be retained, and the two indicators B22 and B23 are excluded.

After calculation, it may be concluded that among the social benefit indicators of the operation of S\&T results in universities, new jobs created (B21) and the growth rate of total labor productivity (B24) are relatively important indicators that affect the social benefits of S\&T results operation in universities, namely, key indicators as screened out. 
In order to pick out the important indicators from the indicator system, data treatment should be performed on economic benefit, social benefit and S\&T innovation using the above methods, so as to obtain performance evaluation indicator system for the S\&T results operation of universities after processing with the GEM, as shown in Table 5.

\section{Variable tree}

The good choice of input and output indicators is the key to the DEA approach, if inappropriate, it will lead to the distortion of the analysis results. Based on the above analysis, data selected for reflecting human inputs includes R\&D personnel (X1) and R\&D researchers' full-time equivalent (X2); the capital investment indicators mainly include internal expenditure of R\&D outlay (X4) and S\&T activity funds (X6), new product development costs (X7), etc. The intellectual property inputs indicators include the patent applications (X8), the patent grants (X9), and the S\&T articles (X10) listed in the three core journals. Outputs indicators select the trademark licensing income (B1), research consulting income (B2), technical service revenue (B3), new product sales revenue (B4), S\&T results transfer income (B5), profit newly added in current year (B6), production cost reduction amount (B7) under the level I economic benefits and new jobs created in current year (B8), total labor productivity growth rate (B9) and S\&T results transfer for the innovation (B10), technology contract turnover (B11), technical contract transactions (B12), national awards (B13), patent applications (B14), and patents internationally granted (B15) under level I social benefits.

In order to access effective data, it is required to choose the universities in the central and west China and in other areas as the study cases for the comparison. Given that the data comparison may be available, this paper needs to choose the technology-applied, "double first-rate" universities, should be the local applied technology undergraduate colleges, the national "double-class" and comprehensive universities in these areas. Data sources in this paper is the $S \& T$ Statistics Book for Institutions of Higher Education in the relevant years.

Table 6

Descriptive Statistical Analysis of Inputs and Outputs

\begin{tabular}{llcccc}
\hline \multirow{2}{*}{ Variable } & \multicolumn{1}{c}{ Statistics } & \multicolumn{3}{c}{ Year } \\
\cline { 3 - 6 } X1 & Mean value & 11928 & 12300 & 2008 & 2009 \\
\cline { 2 - 5 } X2 & Standard deviation & 4948 & 5072 & 8451 & 8260 \\
& Mean value & 2210870 & 2690988 & 7409680 & 8223914 \\
X3 & Standard deviation & 1564218 & 1784905 & 4100749 & 4679169 \\
& Mean value & 3223 & 3386 & 7492 & 8303 \\
X4 & Standard deviation & 2214 & 2468 & 5593 & 5426 \\
& Mean value & 5258 & 5267 & 9728 & 9841 \\
X5 & Standard deviation & 3541 & 2844 & 7486 & 6833 \\
& Mean value & 2022 & 2851 & 2845 & 3830 \\
X6 & Standard deviation & 2998 & 4455 & 3730 & 4788 \\
& Mean value & 6003 & 6621 & 21633 & 21880 \\
X7 & Standard deviation & 4511 & 5564 & 14056 & 14476 \\
& Mean value & 494 & 460 & 395 & 597 \\
Y1 & Standard deviation & 358 & 344 & 366 & 536 \\
& Mean value & 276 & 348 & 2486 & 3186 \\
Y2 & Standard deviation & 334 & 358 & 2292 & 3054 \\
& Mean value & 113 & 130 & 208 & 172 \\
\hline
\end{tabular}


Given the above, the technology-applied colleges and universities includes Jinzhong College, Lanzhou Institute of Technology, Hubei S\&T College and Shanghai Dian Ji University, Zhejiang S\&T College, Chongqing S\&T College; the national "double first-class" universities are Taiyuan University of Technology, Ningxia University, Lanzhou University and South China University of Technology, Shanghai Jiaotong University, Xiamen University; the comprehensive universities are Shanxi University, North University of China, Hebei University and Shandong University, Wuhan University, Zhejiang University; the universities of science and engineering are Taiyuan University of Technology, Anhui University of Science and Technology, Guizhou Institute of Technology and Huazhong S\&T University, Northwestern Polytechnical University, Beijing Institute of Technology.

Since the S\&T Statistics Book for Institutions of Higher Education are not completely consistent in some years, in order to avoid the inconsistency of statistical caliber, this paper chooses the relevant statistical indicators in 2010-2017 as the study sample. The descriptive results from statistical analysis on the selected variables are shown in Table 6 (it is replaced by new one after entering and finding data).

\section{Analysis of results}

\section{Measurement and analysis of transfer efficiency of Chinese University S\&T achievements}

In this paper, the number of Bootstrap iterations is set to 3000. As shown in Table 7, the estimated efficiencies of S\&T results transfer in 24 universities in China in 2001, 2002, 2008 and 2009 are listed in Bootstrap-DEA corrigenda. It is calculated that the mean conversion efficiencies of university S\&T results transfer in 2001, 2002, 2008 and 2009 are 0.64, 0.78, 0.77 and 0.81, respectively, which shows that the transfer efficiency of Chinese university S\&T results is on the rise. The standards for the transfer efficiency of university S\&T results are $0.20,0.18,0.16$ and 0.18 , respectively, showing that the gap in the efficiency of S\&T results between universities does not show a downward trend. The transfer efficiency of Chongqing University in these four years is 1, while that of Shanghai Jiaotong University, Nanjing University, Southeast University, Zhejiang University, Hefei University of Technology and Shandong University showed a significant upward trend.

\section{Analysis of regional characteristic factors of transfer efficiency of Chinese University S\&T achievements}

This paper classifies 24 universities according to their areas into some in the eastern areas (Peking University, Tsinghua University, Nankai University, Tianjin University, Northeastern University, Fudan University, Tongji University, Shanghai Jiaotong University, Nanjing University, Southeast University, Zhejiang University, Xiamen University, Shandong University, Zhongshan University), and some in the central areas (Jilin University, Hefei University of Technology, Wuhan University, Huazhong S\&T University, Hunan University, Central South University) and some in western areas (Chongqing University, Sichuan University, Xi'an Jiaotong University, Lanzhou University). Based on the above calculation results, a comparative analysis of the differences in the transfer efficiencies of S\&T results between these universities in the east, central and west China is performed. Impacted by social, economic, historical and natural factors, there is a certain gap in the economic development between these areas. In 2010, the ratio of per capita net income in China's eastern, central and western areas was 1.95:1.33:1. It can be seen that, in general, the east China is more developed than the central areas, but the latter is more developed than the west China. Moreover, the gap between the east China 
and the central China is wider than that between the central China and the west China. Then, the difference in the average transfer efficiency of university S\&T results between the east, central and west China does not fully explain there are regional differences in the transfer performance of S\&T results among universities in the three areas. The Mann-Whitney U nonparametric statistical test method will be used to test whether there is regional difference in the transfer efficiency of S\&T results between universities in different areas. The test results are shown in Table 7. According to the Mann-Whitney U test, in 2001 and 2002, there were significant differences in the transfer efficiency of S\&T results between universities in the west and east areas. Universities in the west China and central China, as well as those in the central and east China, do not have significant differences in the transfer efficiency of S\&T results. In 2008 and 2009, universities in the west, central, and east China have a significant difference in the transfer efficiency of S\&T results.

Table 7

Estimation of the Correction Efficiency of Bootstrap-Dea in Scientific and Technological Transformation of Chinese Universities

\begin{tabular}{lcccc}
\hline \multirow{2}{*}{ University name } & \multicolumn{3}{c}{ year } \\
\cline { 2 - 5 } Peking Univ & 2001 & 2002 & 2008 & 2009 \\
THU & 0.86 & 1.00 & 0.88 & 0.78 \\
NKU & 1.00 & 1.00 & 0.86 & 0.94 \\
Tianjin Univ & 0.89 & 1.00 & 0.78 & 0.72 \\
NEU & 0.21 & 0.62 & 0.77 & 0.74 \\
JLU & 0.38 & 0.68 & 0.64 & 0.61 \\
Fudan Univ & 0.87 & 0.86 & 0.72 & 0.66 \\
TJU & 0.75 & 0.73 & 0.84 & 0.48 \\
Shanghai Jiao Tong Univ & 0.55 & 0.66 & 0.86 & 0.85 \\
Nanjing Univ & 0.37 & 0.62 & 0.84 & 1.00 \\
SEU & 0.57 & 1.00 & 1.00 & 1.00 \\
Zhejiang Univ & 0.84 & 0.86 & 1.00 & 1.00 \\
HFUT & 0.78 & 0.92 & 1.00 & 1.00 \\
XMU & 0.67 & 0.98 & 1.00 & 1.00 \\
Shandong Univ & 0.68 & 0.77 & 0.86 & 0.96 \\
Wuhan Univ & 0.76 & 0.84 & 0.95 & 1.00 \\
HUST & 0.56 & 1.00 & 0.72 & 0.86 \\
HUNAN UNIV & 0.88 & 0.64 & 0.34 & 0.48 \\
Central South Univ & 0.26 & 0.41 & 0.57 & 0.94 \\
SYSU & 0.34 & 0.87 & 0.29 & 0.31 \\
CHONGQING UNIV & 0.69 & 1.00 & 1.00 & 0.97 \\
Sichuan Univ & 1.00 & 1.00 & 1.00 & 1.00 \\
Xi'an Jiaotong Univ & 0.34 & 0.27 & 0.56 & 1.00 \\
LANZHOU UNIV & 0.64 & 0.55 & 0.76 & 0.69 \\
Mean value & 0.35 & 0.37 & 0.42 & 0.38 \\
Standard deviation & 0.64 & 0.78 & 0.77 & 0.81 \\
\hline
\end{tabular}

\section{Conclusion}

This paper traces the relevant data history from 24 universities in China to evaluate and analyze how the transfer efficiency of S\&T achievements goes for Chinese universities with the Bootstrap-DEA method, these findings suggest that: 
The average transfer efficiencies of S\&T achievements in Chinese universities in 2001, 2002, 2008 and 2009 were $0.64,0.78,0.77$ and 0.81 , respectively, which implies that the transfer efficiency of their S\&T achievements showed an upward trend. There are the standard offsets in the transfer efficiency of S\&T achievements between universities, i.e. $0.20,0.18,0.16$ and 0.18 , respectively. It means that the gap in the transfer efficiency of S\&T achievements between universities has not shown a downward trend. In these four years, the Chongqing University have attained a S\&T transfer efficiency of 1, while the Shanghai Jiaotong University, the Nanjing University, the Southeast University, the Zhejiang University, the Hefei University of Technology and the Shandong University show a significant upward trend in this area.

In 2001 and 2002, there were a big gap in the S\&T transfer efficiency between universities in West and East China, but moderate between universities in west and central China and between those in central and east China. While in 2008 and 2009, there were a large gap in this area between universities in the west, central, and east China.

Regardless of whether it is in the whole country or in the east, the middle and the west China, the per capita GDP of areas where the university lies are all significantly positive for improving its S\&T innovation efficiency. From the estimation results of the whole country and the east and central China, the per capita FDI of areas where the university lies has a significantly positive impact on its S\&T innovation efficiency, but in the west China, it is not significant. There is a little correlation between the per capita expenditure of the funds for science undertakings and the S\&T transfer efficiency between areas, even no correlation between the central and west China, and weak in the east China. There is no correlation between the financial development level and the universities' S\&T transfer efficiency. It means that China's financial development level is still far from enough to provide strong support for the S\&T transfer of universities.

\section{References}

Anderson, T. R., Daim, T. U., \& Lavoie, F. F. (2007). Measuring the efficiency of university technology transfer. Technovation, 27(5), 306-318. https://doi.org/10.1016/j.technovation.2006.10.003

Cai, Y. Z. (2015). Research commercialization: Content, boundary as well as statistics and measuring. Studies in Science of Science, 33(1), 37-44. https://doi.org/10.3969/j.issn.1003-2053.2015.01.006

Coelli, T. J., Rao, D. S. P., O'donnell, C. J., \& Battese, G. E. (2005). An introduction to efficiency and productivity analysis. Springer Science \& Business Media, https://doi.org/10.1007/978-1-4615-5493-6

He, B., \& Fan, S. (2013). The evolution and impact factors of university technology transfer efficiency in China: based on the method of Bootstrap-DEA and panel Tobit model. Science of Science and Management of S. \& $T, 34(10), 85-94$.

He, D. F. (2011). Analysis of and Considerations on the Concepts of Scientific and Technological Achievement and Its Transformation, China Soft Science, 11, 1-7. https://doi.org/10.3969/j.issn.1002-9753.2011.11.001

Li, X. L., \& Yu, X. (2014). Regional triple helix intensity and TTO’s features on TTO's efficiency. Science Research Management. 35(9), 115-122.

Shen, H. Y. (2010). Research of the Development on Chinese Research Universities With industry feature. Harbin Engineering University, https://doi.org/10.7666/d.y1809413 
Siegel, D. S., Waldman, D., \& Link, A. (2003). Assessing the impact of organizational practices on the relative productivity of university technology transfer offices: an exploratory study. Research policy, 32(1), 27-48. https://doi.org/10.1016/S0048-7333(01)00196-2\}

Simar, L., \& Wilson, P. W. (2000). Statistical inference in nonparametric frontier models: The state of the art. Journal of Productivity Analysis, 13(01), 49-78.

Zhao, J., Zhang, J. J., Tang, S. G., \& Di, X. Y. (2011). The study of technology equity in the transformation of scientific. Studies in Science of Science, 29(10), 1485-1489.

Zhao, Z. Y., \& Du, H. L. (2011). Study on the monitoring index system for transformation process of scientific and technical achievements. China Soft Science, 11, 8-14. https://doi.org/10.3969/j.issn.10029753.2011.11.002. 